\title{
Should Postmastectomy Radiotherapy to the Chest Wall and Regional Lymph Nodes Be Standard for Patients with 1-3 Positive Lymph Nodes?
}

\author{
Birgitte V. Offersen ${ }^{\mathrm{a}}$ Hans-Jürgen Brodersen ${ }^{\mathrm{b}} \quad$ Mette M. Nielsen $^{\mathrm{c}} \quad$ Jens Overgaard $^{\mathrm{d}}$ \\ Marie Overgaard ${ }^{a}$, on behalf of the DBCG Radiotherapy Committee \\ ${ }^{a}$ Department of Oncology, Aarhus University Hospital, Denmark \\ ${ }^{b}$ Klinik für Strahlentherapie, Malteser Krankenhaus St. Franziskus-Hospital, Flensburg, Germany \\ 'Department of Oncology, Odense University Hospital, \\ ${ }^{d}$ Department Experimental Clinical Oncology, Aarhus University Hospital, Denmark
}

\section{Keywords}

Postmastectomy radiotherapy - Breast cancer .

Positive lymph nodes · Randomized clinical trial

\section{Summary}

The indication for adjuvant postmastectomy radiotherapy (PMRT) in breast cancer patients with small tumors and 1-3 macrometastases in the axilla remains a controversial issue, despite the recommendation that PMRT should be applied in these patients in the most recent overview by the Early Breast Cancer Trialists' Collaborative Group. In this report, we discuss the available data on the benefit from PMRT in patients diagnosed with N1 breast cancer. Based on this, we recommend adjuvant PMRT to the chest wall and regional lymph nodes in patients diagnosed with early node-positive breast cancer.

\section{Introduction}

The indication for adjuvant postmastectomy radiotherapy (PMRT) in breast cancer patients operated on for small tumors with 1-3 macrometastases in the axilla remains a controversial issue, despite the recommendation that PMRT should be applied in these patients in the most recent overview by the Early Breast Cancer Trialists' Collaborative Group (EBCTCG) [1]. In that overview, a survival benefit from PMRT was documented and a proportional risk reduction was seen between the lower risk of locoregional recur-

\author{
Schlüsselwörter \\ Postmastektomie-Radiotherapie - Mammakarzinom . \\ Positive Lymphknoten - Randomisierte klinische Studie
}

\section{Zusammenfassung}

Die Indikation für adjuvante Postmastektomie-Radiotherapie (PMRT) bei Brustkrebspatienten mit kleinen Tumoren und 1-3 Makrometastasen in der Axilla wird trotz entsprechender Empfehlungen in der jüngsten Auswertung der Early Breast Cancer Trialists' Collaborative Group noch immer kontrovers diskutiert. In der vorliegenden Übersichtsarbeit werden die verfügbaren Daten zum Benefit der PMRT bei Patienten mit N1-Mammakarzinomen diskutiert. Demnach empfehlen wir adjuvante PMRT der Thoraxwand und der regionalen Lymphknoten bei Patienten mit einem primären Mammakarzinom und Lymphknotenbefall.

\section{KARGER}

Fax +497614520714

Information@Karger.de

www.karger.com

\section{(c) 2011 S. Karger GmbH, Freiburg}

$1661-3791 / 11 / 0065-0347 \$ 38.00 / 0$

Accessible online at:

www.karger.com/brc rence (LRR) and improved survival. In several consensus and guideline reports, adjuvant PMRT has been recommended in patients operated on for $4+$ positive nodes, but not in the situation of 1-3 positive nodes as the only criterion [2-8]. However, in the most recent consensus report from St. Gallen 2009, the use of PMRT in patients with 1-3 macrometastases in the axilla was recommended if the patient was young and for those with other poor prognostic features [9]; however, age and poor markers were not further defined. In this report, we discuss the evidence available regarding the benefit from adjuvant radiotherapy after surgery for N1 breast cancer. 


\section{The DBCG Postmastectomy Studies}

The 2 largest and most recent randomized trials investigating the benefit from adjuvant radiotherapy to the chest wall and regional lymph nodes in N1 breast cancer after mastectomy are the DBCG $82 \mathrm{~b}$ and $\mathrm{c}$ trials by the Danish Breast Cancer Cooperative Group (DBCG) [10-19]. In the DBCG $82 \mathrm{~b}$ and $\mathrm{c}$ trials, 3,083 pre- and postmenopausal high-risk breast cancer patients were randomized to $+/-$ adjuvant PMRT in addition to their systemic therapy. In the DBCG $82 \mathrm{~b}$ protocol, 1,708 pre- and perimenopausal patients were included, and in the DBCG 82 c protocol, 1,375 postmenopausal patients below 70 years of age were included. The protocols were open for inclusion in the period of 1982-1990, and the high-risk criteria at that time were node-positive disease and/or a T3 or T4 tumor and/or skin or deep fascia invasion.

Based on the surgical guidelines used during the period of inclusion in these protocols, the median number of removed lymph nodes was 7 . Therefore, in the following we discuss results from a selected subgroup of 1,152 node-positive patients where 8 or more lymph nodes were removed during surgery. The surgical treatment was macroradical mastectomy and axillary dissection with the aim to remove the nodes of level I and partly level II and all macroscopically enlarged nodes. The systemic therapy in the premenopausal patients consisted of 8-9 cycles of CMF (cyclophosphamide, methotrexate, 5-fluorouracil), and for the postmenopausal patients tamoxifen $30 \mathrm{mg}$ daily for 48 weeks (further details in [10, 11]). Patients randomized to radiotherapy were treated with 48-50 Gy in 22-25 fractions, 5 weeks. The radiotherapy fields included the thorax wall, the internal mammary nodes, and the periclavicular and axillary nodes. Further details are given in [14]. After a median follow-up of 18 years (range 15-22 years), a substantial and equal survival benefit from locoregional PMRT was documented in patients with 1-3 and $4+$ positive lymph nodes in the axilla [12]. During the first 15 years post treatment, 179 patients $(16 \%)$ were diagnosed with LRR and 762 patients $(66 \%)$ died. The frequency of LRR in the radiotherapy group was $4 \%$ and in the noneradiotherapy group 26\%; the corresponding 15-year actuarial values were 6 and $37 \%$, respectively, $\mathrm{p}<0.001$, and relative risk (RR) 0.12 (95\% confidence interval (CI) $0.07-0.19$ ). Using the endpoint overall survival, $61 \%$ had died in the radiotherapy group and $71 \%$ in the none-radiotherapy group; the 15-year actuarial values were 39 and 29\%, respectively, $\mathrm{p}=0.015$, and RR 0.63 (95\% CI 0.49-0.81). Morbidity from PMRT was evaluated in these patients, and importantly no excess cardiac mortality was identified after a median followup of 12 years $[13,19]$. Results from the RACE study have recently confirmed no differences in cardiac morbidity and mortality between Danish patients irradiated with PMRT for left- and right-sided breast cancer [20].

In 1,000 patients included in the DBCG $82 \mathrm{~b}$ and $\mathrm{c}$ trials, tumor tissue was available for further examination. Thus immunohistochemical studies of classical histopathologic parameters such as estrogen receptors (ER) and progesterone receptors and HER2 status together with $\mathrm{T}$ and $\mathrm{N}$ status were related to the pattern of recurrence in the irradiated and nonirradiated patients [17]. This showed that in the patients with 'good prognosis' defined as pT1, pN1, grade 1, ER+, and HER2-, there was a 1:1 relationship between LRR and overall survival (in the non-irradiated group, $11 \%$ more LRR after 5 years translated into $12 \%$ worse overall survival after 15 years). In the subgroup of worst prognosis defined as pT3+, $\mathrm{pN} 2+$, and grade 3 , there was a difference of $35 \%$ more LRR in the non-irradiated group after 5 years but this did no result in any difference in overall survival after 15 years. The conclusion therefore was that the irradiated patients with the best prognosis in both the DBCG $82 \mathrm{~b}$ and c trials had significantly better locoregional control and a significant gain in overall survival of the same magnitude.

\section{Other Studies Evaluating the Benefit from Adjuvant Postoperative Radiotherapy}

\section{The British Columbia Randomized Trial}

Parallel to the DBCG 82 b trial, a Canadian randomized trial on adjuvant radiotherapy in 318 premenopausal women treated with modified radical mastectomy and adjuvant chemotherapy (9 cycles of CMF) was conducted. In the period of 1979-1986, patients were randomized to +/- adjuvant PMRT with 37.5 Gy in 16 fractions to the chest wall and regional lymph nodes including the internal mammary nodes. A median 11 lymph nodes were removed, and 183 patients were diagnosed with 1-3 positive nodes whilst 112 patients had $4+$ nodes [21, 22]. The results from this study were in harmony with the DBCG trial, demonstrating significant improvements in all evaluated endpoints in favor of PMRT at the 20-year follow-up. In particular the Canadian group reported survival free of isolated LRR (74 vs. $90 \%$, RR 0.36 ; $95 \%$ CI $0.18-0.71 ; \mathrm{p}=0.002)$, breast cancer-free survival (48 vs. $30 \%$, RR 0.63 ; 95\% CI 0.47-0.83; p = 0.001), and overall survival (47 vs. $37 \%$, RR 0.73 ; $95 \%$ CI $0.55-0.98$; $\mathrm{p}=0.03$ ). Long-term toxicities were evaluated and were minimal in both arms.

\section{MA25 Trial}

The MA25 trial tested the effect of adding locoregional PMRT in patients with N1 disease. The trial was lead by the SWOG (South Western Oncology Group) but unfortunately accrued very slowly in the period from 1999 to 2003 when it was closed due to poor inclusion.

\section{MA20 Trial}

The MA20 trial conducted by the National Cancer Institute of Canada Clinical Trials Group enrolled 1,832 patients between 2000 and 2007, and the first results were reported at ASCO 
2011 with 62 months median follow-up [23]. Patients with high-risk node-negative or node-positive breast cancer had breast conserving surgery followed by whole breast irradiation and were randomized to $+/-$ regional radiotherapy. All patients with $\mathrm{N} 1$ disease ( $85 \%$ of the cohort) were treated with level I and II axillary dissection, adjuvant chemotherapy, and/or endocrine therapy. Among the 916 patients in the group treated with regional radiotherapy, the internal mammary, supraclavicular, and apical axillary lymph nodes were included in the radiotherapy fields. The results demonstrated a significantly better outcome for those patients treated with regional radiotherapy for the following endpoints: diseasefree survival (DFS) (hazard ratio (HR) 0.68 ; 95\% CI 0.52 $0.87 ; \mathrm{p}=0.003$ ), isolated locoregional DFS (HR 0.59; 95\% CI $0.37-0.92 ; \mathrm{p}=0.02$ ), distant DFS (HR 0.64; 95\% CI 0.47-0.85; $\mathrm{p}=0.002)$, and a trend towards better overall survival was observed (HR 0.76; 95\% CI 0.56-1.03; $\mathrm{p}=0.07$ ).

\section{The SUPREMO Trial}

A third randomized study is the SUPREMO trial which includes patients after mastectomy for intermediate risk breast cancer (1-3 positive nodes or invasive ductal carcinoma grade III), and these patients are randomized to either no irradiation or chest wall irradiation with no regional radiotherapy. The SUPREMO study started in June 2006 and by now has enrolled more than 1,100 patients from more than 120 centers. The trial is on track to meet the target of 1,600 patients recruited by December 2012. The first report on the secondary endpoints is planned for around June 2016 when all patients will have a minimum of 3 years follow-up and the median follow-up will be around 5 years. The primary analysis will be completed in 2023 when all patients will have a minimum of 10 years follow-up (personal communication Eve Macdonald, National Scotland Services).

\section{The EORTC 22922/10925 Trial}

In 2012, the first results from the EORTC 22922/10925 randomized phase III trial are expected. In the period of 19962004, 4,004 patients with localized stage I-III breast cancer medially or centrally located in the breast and/or node-positive disease were randomized to $+/$ - elective irradiation of the internal mammary nodes and the medial supraclavicular lymph node regions [24]. Only $23 \%$ of the patients in that trial received a mastectomy.

\section{Results from Canada after Changing PMRT Guidelines}

In 1997 and 1998, the results from the 2 large randomized clinical trials investigating the benefit from irradiation of the regional lymph nodes in the postmastectomy situation in Denmark and Canada were published [10-12, 25, 26]. These results stimulated an increased use of regional radiotherapy also in patients having undergone breast conserving surgery in British Columbia. Parallel to the MA20 trial, patients with N1 disease were offered regional radiotherapy outside the proto- col, and recently the positive outcome in these patients has been reported in a cohort of 2,768 patients [27]. Before 1997, locoregional radiotherapy was offered to $23 \%$ of patients with N1 disease, and after 1997 this figure increased to $57 \%$. This resulted in a significantly better locoregional control rate, with the 10 -year local control rate being $89 \%$ without and $93 \%$ with locoregional radiotherapy $(\mathrm{p}=0.006)$. In multivariate analysis, locoregional radiotherapy was associated with improved locoregional control (HR 0.55; 95\% CI 0.40-0.77).

\section{The German Guidelines for PMRT to N1 Breast Cancer Patients}

In the first evidence-based guideline from the German Cancer Society (Deutsche Krebsgesellschaft, DKG) in 2004, the use of PMRT was recommended only in patients with micro- or macroscopic residual disease (R1-2 situation), with $4+$ positive nodes, $\mathrm{pT} 3+$ tumors $>5 \mathrm{~cm}$ (Grade of Recommendation GR A), and patients with special risks [28]. These risk factors were specified in 2005 by the German Society of Radiooncology (Deutsche Gesellschaft für Radioonkologie, DEGRO): 1-3 positive nodes (GR B); age $<40$ years, L+ or $\mathrm{V}+$ (lymph- or hemangiosis), pT2 $>3 \mathrm{~cm}, \mathrm{G} 3$, multicentric or multifocal tumors, infiltration of the pectoral fascia or margin $<5 \mathrm{~mm}$ (GR C) [29]. Since randomized studies demonstrated a significant survival benefit for irradiated patients irrespective of the number of affected nodes, the debate regarding PMRT was resumed in Germany in 2007 [30], and the first update of the DKG guidelines described PMRT in patients with 1-3 positive nodes as exerting a possible benefit (Level of Evidence (LOE) 1a, GR 0) [31]. The common consensus from 2008 until today is described in the DEGRO Practical Guidelines for Radiotherapy of Breast Cancer II [32]: PMRT to the chest wall decreases the local recurrence rate (LOE 1a). In patients with a high risk of local recurrence, PMRT improves survival (LOE 1a). PMRT to the chest wall is indicated in patients with T3/T4 tumors (LOE 2a, GR A), $\mathrm{R} 1 / \mathrm{R} 2$ resection (LOE $2 \mathrm{a}, \mathrm{GR} \mathrm{A})$ or $\mathrm{pN}+(>3)$ ( $\mathrm{LOE} 1 \mathrm{a}$, GR A). Patients with 1-3 positive axillary nodes may benefit from PMRT (LOE 1a, GR 0). The conclusion of the DEGRO Panel is therefore that for patients with 1-3 positive axillary nodes bearing an intermediate risk for LRR after mastectomy, PMRT should no longer be considered optional but an indication based on strong evidence (LOE 1). As a consequence, in the next update of DKG the respective recommendation should be modified accordingly. The significance of other risk factors such as age $<40$ years, blood or lymphatic vessel invasion, infiltration of the pectoral fascia, or close resection margins $<1 \mathrm{~mm}$ has not been definitively assessed; therefore, the respective benefit of PMRT is not yet quantifiable on a high LOE. As radiotherapy may prevent secondary distant spread by reducing local recurrence, the panel recommends PMRT in these situations, especially in patients with 
Table 1. Results of different studies on adjuvant radiotherapy to patients with nodepositive breast cancer

\begin{tabular}{|c|c|c|c|c|c|}
\hline Study [ref.] & $\begin{array}{l}\text { Inclusion } \\
\text { period }\end{array}$ & $\begin{array}{l}\text { Patients, } \mathrm{n} \\
(\mathrm{N} 1, \%)\end{array}$ & Randomization & $\begin{array}{l}\text { Median } \\
\text { follow-up, } \\
\text { years }\end{array}$ & Results \\
\hline DBCG $82 \mathrm{~b}$ and c [12] & $1982-1990$ & $1,152^{\mathrm{a}}(48)$ & $\begin{array}{l}+/- \text { PMRT to chest wall and } \\
\text { regional lymph nodes including } \\
\text { internal mammary lymph nodes }\end{array}$ & 18 & $\begin{array}{l}15 \text { years actuarial values: LRR 6\% } \\
\text { (+RT) vs. } 37 \% \text { (-RT); OS 39\% } \\
\text { (+RT) vs. } 29 \% \text { (-RT) }\end{array}$ \\
\hline $\begin{array}{l}\text { British Columbia Random- } \\
\text { ized Trial [22] }\end{array}$ & 1979-1986 & $318(58)$ & $\begin{array}{l}+/- \text { PMRT to chest wall and } \\
\text { regional lymph nodes including } \\
\text { internal mammary lymph nodes }\end{array}$ & 20 & $\begin{array}{l}\text { survival free from isolated LRR } 90 \% \\
\text { (+RT) vs. } 74 \% \text { (-RT); BCFS } 48 \% \\
(+\mathrm{RT}) \text { vs. } 30 \%(-\mathrm{RT}) ; \mathrm{OS} 47 \% \\
(+\mathrm{RT}) \text { vs. } 37 \%(-\mathrm{RT})\end{array}$ \\
\hline MA20 [23] & 2000-2007 & $1,832(85)$ & $\begin{array}{l}\text { WBI +/- RT to regional lymph } \\
\text { nodes }\end{array}$ & 5 & $\begin{array}{l}\text { in favor of regional RT: DFS HR } \\
0.59, \mathrm{p}=0.02 \text {; distant DFS HR: } 0.64 \text {, } \\
\mathrm{p}=0.002 ; \text { OS HR } 0.76, \mathrm{p}=0.07\end{array}$ \\
\hline SUPREMO & 2006-2012 & target 1,600 & $+/-\mathrm{RT}$ to chest wall & & awaited June 2016 \\
\hline EORTC 22922/10925 [24] & 1996-2004 & $4,004(42)$ & $\begin{array}{l}\text { +/- RT to IMN and medial } \\
\text { supraclavicular lymph nodes }\end{array}$ & & awaited 2012 \\
\hline $\begin{array}{l}\text { British Columbia cohort } \\
\text { treated outside trial [27] }\end{array}$ & $1997-$ & $2,768(100)$ & & & $\begin{array}{l}\text { 10-year local control rate } 89 \% \text { with- } \\
\text { out locoregional RT and } 93 \% \text { with } \\
\text { locoregional RT, HR } 0.55, \mathrm{p}=0.006\end{array}$ \\
\hline
\end{tabular}

several of the above-mentioned risk factors. The second update of the DKG guideline is expected at the beginning of 2012, but in the preliminary statement of the German Gynecological Oncology Working Group (Arbeitsgemeinschaft Gynäkologische Onkologie, AGO) in 2011, PMRT is recommended in patients with 1-3 positive nodes with an LOE 1a A + (depending on the age of the patient) [33].

\section{Recommendations}

The results from the different studies are summarized in table 1 . The results from the DBCG $82 \mathrm{~b}$ and $\mathrm{c}$ trials showed a clear benefit with regard to locoregional control and overall survival from adjuvant radiotherapy to the chest wall and locoregional lymph nodes in postmastectomy patients diagnosed with 1-3 positive axillary lymph nodes. These results were strongly supported by the results from The British Columbia Randomized Trial, and lately the results from the MA20 Trial have further confirmed the benefit from regional radiotherapy after breast conservation. Importantly, the systemic therapy in the MA20 Trial is more modern than the systemic therapy in the trials from the 1980ies, but still a sig- nificant improvement in locoregional and distant DFS is seen among irradiated patients. Due to different selection of patients to the running trials mentioned above, combined with the different targets for the adjuvant radiotherapy, it is clear that the running trials will not be able to answer the question of the effect of regional radiotherapy in the postmastectomy patient operated on for N1 breast cancer. We strongly recommend that all patients with $1-3$ and $4+$ positive lymph nodes receive locoregional radiotherapy. The results indicate an equal gain in locoregional control by radiotherapy for patients with both 1-3 and 4+ positive nodes.

\section{Acknowledgement}

This study was supported by a grant from CIRRO (The Lundbeck Foundation Centre for Interventional Research in Radiation Research), the Danish Research Council, and the Danish Cancer Society.

\section{Disclosure Statement}

The authors declare no conflict of interest.

\section{References}

1 Clarke M, Collins R, Darby S, Davies C, Elphinstone P, Evans E, et al.: Effects of radiotherapy and of differences in the extent of surgery for early breast cancer on local recurrence and 15 year survival: an overview of the randomised trials. Lancet 2005;366:2087-106.
2 Harris JR, Halpin-Murphy P, McNeese M, Mendenhall NP, Morrow M, Robert NJ: Consensus statement on postmastectomy radiation therapy. Int J Radiat Oncol Biol Phys 1999;44:989-90.
3 Recht A, Edge SB, Solin LJ, Robinson DS, Estabrook A, Fine RE, et al.: Postmastectomy radiotherapy: clinical practice guidelines of the American Society of Clinical Oncology. J Clin Oncol 2001;19:1539-69. 
4 Eifel P, Axelson JA, Costa J, Crowley J, Curran WJ Jr, Deshler A, et al.: National Institutes of Health Consensus Development Conference Statement: adjuvant therapy for breast cancer, November 1-3, 2000. J Natl Cancer Inst 2001;93:979-89.

$\checkmark 5$ Kurtz J: The curative role of radiotherapy in the treatment of operable breast cancer. Eur J Cancer 2002;38:1961-74.

6 Goldhirsch A, Wood WC, Gelber RD, Coates AS, Thurlimann B, Senn HJ: Meeting highlights: updated international expert consensus on the primary therapy of early breast cancer. J Clin Oncol 2003;21:3357-65.

7 Truong PT, Olivotto IA, Whelan TJ, Levine M: Clinical practice guidelines for the care and treatment of breast cancer: 16. Locoregional postmastectomy radiotherapy. CMAJ 2004;170:126373.

8 Goldhirsch A, Glick JH, Gelber RD, Coates AS, Thurlimann B, Senn HJ: Meeting highlights: international expert consensus on the primary therapy of early breast cancer 2005. Ann Oncol 2005;16:1569-83.

$\checkmark 9$ Goldhirsch A, Ingle JN, Gelber RD, Coates AS, Thurlimann B, Senn HJ: Thresholds for therapies: highlights of the St Gallen International Expert Consensus on the primary therapy of early breast cancer 2009. Ann Oncol 2009;20:1319-29.

10 Overgaard M, Jensen MB, Overgaard J, Hansen PS, Rose C, Andersson M, et al.: Postoperative radiotherapy in high-risk postmenopausal breastcancer patients given adjuvant tamoxifen: Danish Breast Cancer Cooperative Group DBCG 82c randomised trial. Lancet 1999;353:1641-8.

11 Overgaard M, Hansen PS, Overgaard J, Rose C, Andersson M, Bach F, et al.: Postoperative radiotherapy in high-risk premenopausal women with breast cancer who receive adjuvant chemotherapy. Danish Breast Cancer Cooperative Group 82b Trial. N Engl J Med 1997;337:949-55.

12 Overgaard M, Nielsen HM, Overgaard J: Is the benefit of postmastectomy irradiation limited to patients with four or more positive nodes, as recommended in international consensus reports? A subgroup analysis of the DBCG $82 \mathrm{~b}$ and c randomized trials. Radiother Oncol 2007;82:24753.

13 Hojris I, Overgaard M, Christensen JJ, Overgaard $\mathrm{J}$ : Morbidity and mortality of ischaemic heart disease in high-risk breast-cancer patients after adjuvant postmastectomy systemic treatment with or without radiotherapy: analysis of DBCG $82 \mathrm{~b}$ and $82 \mathrm{c}$ randomised trials. Radiotherapy Committee of the Danish Breast Cancer Cooperative Group. Lancet 1999;354:1425-30.

14 Nielsen HM, Overgaard J, Grau C, Christensen JJ, Overgaard M: Audit of the radiotherapy in the DBCG $82 \mathrm{~b}$ and c trials - a validation study of the 1,538 patients randomised to postmastectomy radiotherapy. Radiother Oncol 2005;76:285-92.
15 Nielsen HM, Overgaard M, Grau C, Jensen AR, Overgaard J: Study of failure pattern among high-risk breast cancer patients with or without postmastectomy radiotherapy in addition to adjuvant systemic therapy: long-term results from the Danish Breast Cancer Cooperative Group DBCG $82 \mathrm{~b}$ and $\mathrm{c}$ randomized studies. J Clin Oncol 2006;24:2268-75.

16 Nielsen HM, Overgaard M, Grau C, Jensen AR, Overgaard J: Loco-regional recurrence after mastectomy in high-risk breast cancer - risk and prognosis. An analysis of patients from the DBCG $82 \mathrm{~b}$ and $\mathrm{c}$ randomization trials. Radiother Oncol 2006;79:147-55.

17 Kyndi M, Overgaard M, Nielsen HM, Sorensen FB, Knudsen H, Overgaard J: High local recurrence risk is not associated with large survival reduction after postmastectomy radiotherapy in high-risk breast cancer: a subgroup analysis of DBCG 82 b and c. Radiother Oncol 2009;90:74-9.

18 Kyndi M, Sorensen FB, Knudsen H, Overgaard M, Nielsen HM, Overgaard J: Estrogen receptor, progesterone receptor, HER-2, and response to postmastectomy radiotherapy in high-risk breast cancer: the Danish Breast Cancer Cooperative Group. J Clin Oncol 2008;26:1419-26.

19 Hojris I, Andersen J, Overgaard M, Overgaard J: Late treatment-related morbidity in breast cancer patients randomized to postmastectomy radiotherapy and systemic treatment versus systemic treatment alone. Acta Oncol 2000;39:355-72.

20 McGale P, Darby S, Hall P, Adolfsson J, Bengtsson N-O, Bennet AM, et al.: Incidence of heart disease in 35,000 women treated with radiotherapy for breast cancer in Denmark and Sweden. Radiother Oncol 2011;100:167-75.

21 Ragaz J, Jackson SM, Le N, Plenderleith IH, Spinelli JJ, Basco VE, et al.: Adjuvant radiotherapy and chemotherapy in node-positive premenopausal women with breast cancer. N Engl J Med 1997;337:956-62.

22 Ragaz J, Olivotto IA, Spinelli JJ, Phillips N, Jackson SM, Wilson KS, et al.: Locoregional radiation therapy in patients with high-risk breast cancer receiving adjuvant chemotherapy: 20-year results of the British Columbia randomized trial. J Natl Cancer Inst 2005;97:116-26.

23 Whelan T, Olivotto IA, Ackerman I, Chapman JW, Chua B, Nabid A, Vallis KA, White JR, Rousseau P, Fortin A, Pierce L, Manchul LA, Craighead P, Nolan MC, Bowen J, McCready DR, Pritchard KI, Levine M, Parulekar W: NCICCTG MA.20: an intergroup trial of regional nodal irradiation in early breast cancer. J Clin Oncol 2011;29:779s(abstr LBA1003).

24 Matzinger O, Heimsoth I, Poortmans P, Collette L, Struikmans H, Van Den BW, et al.: Toxicity at three years with and without irradiation of the internal mammary and medial supraclavicular lymph node chain in stage I to III breast cancer (EORTC trial 22922/10925). Acta Oncol 2010;49:24-34.
5 Ragaz J, Jackson SM, Le N, Plenderleith IH, Spinelli JJ, Basco VE, et al.: Adjuvant radiotherapy and chemotherapy in node-positive premenopausal women with breast cancer. N Engl J Med 1997;337:956-62.

26 Ragaz J, Olivotto IA, Spinelli JJ, Phillips N, Jackson SM, Wilson KS, et al.: Locoregional radiation therapy in patients with high-risk breast cancer receiving adjuvant chemotherapy: 20-year results of the British Columbia randomized trial. J Natl Cancer Inst 2005;97:116-26.

27 Wai ES, Lesperance M, Speers CH, Truong PT, Jones S, Tyldesley S, et al.: Increased use of regional radiotherapy is associated with improved outcome in a population-based cohort of women with breast cancer with 1-3 positive nodes. Radiother Oncol 2010;97:301-6.

28 Kreienberg R, Kopp I, Lorenz W: Diagnostik, Therapie und Nachsorge des Mammakarzinoms der Frau. Deutsche Krebsgesellschaft, Informationszentrum für Standards in der Onkologie, 2004: AWMF-Register-Nr. 032/045. www.awmf.org/ leitlinien/dokumentenarchiv.html; www.klinikumlippe.de/fileadmin/media/pdf/Kliniken_Radiologie_ S3Leitlinien.pdf, 2011.

29 Radiotherapie des Mammakarzinoms - Version 2005, Deutsche Gesellschaft für Radioonkologie e.V. (DEGRO). www.degro.org/dav/html/download/pdf/Leitlinie_MammaCa.pdf, 2011.

30 Sautter-Bihl ML, Sauer R: One more change of paradigm in breast cancer treatment. Postmastectomy radiotherapy for patients with one to three lymph node metastases? Strahlenther Onkol 2007; 183:357-9.

31 Interdisciplinary S3 Guidelines for the Diagnosis, Treatment and Follow-up Care of Breast Cancer, 1st updated version 2008, Information Center for Standards in Oncology (ISTO), Deutsche Krebsgesellschaft e.V. www.awmf.org/fileadmin/ user_upload/Leitlinien/032_D_Krebsgesellschaft/ Gynaekologie/032-045e_S3_Diagnosis_Treatment_ and_Follow-up_Care_of_Breast_Cancer_04-2008_ 12-2010.pdf. 2011.

32 Sautter-Bihl ML, Souchon R, Budach W, Sedlmayer F, Feyer P, Harms W, et al.: DEGRO practical guidelines for radiotherapy of breast cancer II. Postmastectomy radiotherapy, irradiation of regional lymphatics, and treatment of locally advanced disease. Strahlenther Onkol 2008;184:347-53.

33 Arbeitsgemeinschaft Gynäkologische Onkologie e.V. (AGO/DKG), Diagnostik und Therapie primärer und metastasierter Mammakarzinome - Adjuvante Strahlentherapie, Guidelines Breast Version 2011.1D www.ago-online.de/_download/ unprotected/g_mamma_11_1_0_d_09_adjuvant_ radiation_therapy.pdf, 2011. 